Keynote at the Nordic Intercultural Communication Conference

Intercultural Negotiations

Johan Larsson

Jönköping University

Jönköping International Business School

P.O. Box 1026

SE-551 11 Jönköping

Sweden

johan.larsson@ju.se 


\section{Intercultural Negotiations}

It is impossible to think about a world without negotiations, and in fact most of us negotiate several times a day. But does that imply that all of us are skilled negotiators? Probably not but negotiation skills can be trained and developed (e.g. Thompson, 2002). Not all negotiations are hard but negotiations in business often entail complex situations that involve people at different levels, from different companies' etc. making negotiations a complex activity (Raiffa, 2002). A further challenge is presented when the counterparts not only represent different companies but also different countries and cultures (Liu, Friedman, Barry, Gelfand, Zhang, 2012; Francis, 1991) which highlights the importance of intercultural negotiations which also is the title of the key-note.

The keynote firstly address two major negotiation types namely, distributive negotiations and integrative negotiations (Raiffa, 2002) as well as explaining the BATNA concept (Fisher \& Ury, 1981).

Secondly, some challenges in intercultural negotiations is presented and discussed (Francis, 1991; Liu et al, 2012; Thompson, 2012) as well as being analyzed using the two main negation types presented.

The speaker has worked with professional negotiations domestically as well as international with Asian counterparts, and will draw upon his experience when discussing the differences and challenges to further illustrate this complex matter. The keynote is concluded with some general comments and advice related to intercultural negotiations

Key words: keynote, intercultural, negotiations

\section{References:}

Fisher, R. \& Ury, W. (1981), Getting to Yes, Penguin Books

Francis, J. N. P. (1991), "When in Rome? The effects of cultural adaption on intercultural business negotiations”, Journal of International Business Studies, Third quarter 1991, pp. 403-428

Liu, L A, Friedman, R, Barry, B, Gelfand M J, Zhang, Z. (2012), “The dynamics of consensus building in intracultural and intercultural negotiations", Administrative Science Quarterly, No 57, pp. 269-304

Raiffa, H. (2002), Negotiation Analysis, Harvard University Press

Thompson, L. (2012), The Mind and Heart of the Negotiator, Pearson 